\title{
Increased Levels of IL-10, IL-12, and IFN- $\gamma$ in Patients with Visceral Leishmaniasis
}

\author{
Khoshdel A. ${ }^{1}$, Alborzi A. ${ }^{2}$, Rosouli M. ${ }^{2}$, Taheri E. ${ }^{3}$, Kiany S. ${ }^{2}$ and Javadian M.H. ${ }^{2}$ \\ ${ }^{1}$ Shahrekord University of Medical Sciences, Shahrekord; ${ }^{2}$ Alborzi Clinical Microbiology Research Center, Nemazi Hospital, Shiraz University of \\ Medical Sciences, Shiraz; ${ }^{3}$ Office of Vice Chancellor for Research Affairs, Shahrekord University of Medical Sciences, Shahrekord; Iran
}

\begin{abstract}
Visceral leishmaniasis remains a serious public health problem in developing countries. Cytokines have a crucial role in the pathogenesis of this disease. We evaluated plasma levels of IL-10, IL-12 and IFN- $\gamma$ in 32 patients with active visceral lieshmaniasis, in 29 siblings of the patients and in 23 normal individuals in an endemic area to look for correlations between the clinical outcome of infection and the plasma cytokine levels. An analysis was made with a skin test and a quantitative sandwich enzyme immunoassay. Data were analyzed with the Mann Whitney test and the Kruskal Wallis test. The cytokine levels were significantly higher in the patients than in the control groups. We concluded that normalization of the plasma level of IFN- $\gamma$ can serve as a reliable parameter for considering the patient as cured.
\end{abstract}

Key-Words: Visceral leishmaniasis, interleukin, interferon.

Visceral leishmaniasis (VL), also known as Kalaazar, is an important health problem in developing countries and is endemic in theMiddle East and Mediterranean regions [1,2]. Northwestern and southern Iran are focal regions for VL, which mainly affects children; consequently, Leishmania infantum is expected to be the dominant type of leishmania in Iran $[3,4]$. This disease can be asymptomatic, subclinical and self limiting or can develop into clinically manifesting disease $[5,6]$.

The factors that determine the development or not of $\mathrm{VL}$ have not yet been completely identified, but a leishmania specific cellular immune response seems to play a fundamental role in the control of infection $[7,8]$. We know that resistance to disease in VL is determined by an appropriate type 1 response, whereas susceptibility is mediated by a type 2 response, characterized by the stimulation of high titers of antibody production [9]. In VL, susceptibility is associated with an inability to produce a macrophage - stimulating cytokine profile (Th1 profile), including interferon gamma (IFN$\gamma$ ) and interleukin -12 (IL-12); instead, production of immunosuppressive cytokines, such as interleukin 10 (IL-10), (Th2 profile) is observed (10).

Few studies have examined the production of cytokines in the families of patients and normal individuals in endemic areas. We evaluated the plasma levels of INF- $\gamma$, IL-10, and IL12 in patients with VL and in their asymptomatic siblings in order to determine if there was a correlation between the clinical symptoms of the disease and cytokine production.

\section{Material and Methods}

All patients admitted with a diagnosis of VL in the infectious disease ward of Nemazi hospital, Shiraz, Iran, were categorized as Group I. Group I consisted of 32 cases newly

Received on 12 June 2008; revised 6 December 2008.

Address for correspondence: Dr. Abolfazl Khoshdel. Hajar Hospital, Pediatric Department, Shahrekord University of Medical Sciences, Shahrekord, Iran. Phone: 98381-3337419. Fax: 98381-2221669. Email: nikakhosh@gmial.com.

The Brazilian Journal of Infectious Diseases 2009;13(1):44-46. (C) 2009 by The Brazilian Journal of Infectious Diseases and Contexto Publishing. All rights reserved. identified as VL patients, based on clinical manifestation of kalaazar, such as anemia, hepatosplenomegally, fever, with a positive bone marrow smear, or IFA (immunoflurescent antibody) $\geq 1 / 128$. Group II consisted of 29 asymptomatic siblings of these patients living in the endemic area. Group III consisted of 27 asymptomatic individuals from the same endemic area with a positive leishmania skin test, as a control group.

Leishmanin for the skin test was prepared by the Pasteur Institute; $0.1 \mathrm{~mL}$ of a diluted solution was injected intradermally into the extensor surface of both forearms; induration $\geq 5 \mathrm{~mm}$ $48 \mathrm{~h}$ after injection indicated a positive leishmania skin test.

After diagnosis of VL in 32 cases, (Group I) a blood sample (about $3 \mathrm{~mL}$ ) was obtained from each patient before treatment; serum samples were maintained at $-70^{\circ} \mathrm{C}$.

After the skin test, a blood sample was obtained from Group III (control) individuals and the plasma was stored at $20^{\circ} \mathrm{C}$ in the field and subsequently at $-70^{\circ} \mathrm{C} \mathrm{c}$ until tested. The same procedure was used for siblings of the patients with VL. Plasma levels of IL-10, IL-12, IFN- $\gamma$ were titered by sandwich ELISA (Biosource, USA), according to the manufacturer's protocol. The minimum titrable plasma level of these cytokines is 1 picogram $/ \mathrm{mL}$, levels below that were considered as zero. The results were analyzed by the Mann-Whitney test and the Kruskal -Wallis test using SPSS software.

This study was approved by the Research Ethics Committee of Shiraz medical university and all individuals included in this project, or their legal guardians, signed an informed consent form before enrollment.

\section{Results}

Among 32 patients admitted with a diagnosis of visceral leishmaniasis, 19 cases were female and 13 were male. The IFA was positive for 25 patients and 28 of them had a positive bone marrow smear. The IFA titer was $1 / 250$ for four patients and $1 / 128$ in 21 cases.

In three patients, IFA titer was $1 / 40$ and the bone marrow smears were positive for VL; while in four cases, the IFA titer was $1 / 64$ and the bone marrow smear was negative, but there were clinical manifestations and recovery after treatment. 
Table 1. Cytokine plasma levels in visceral leishmaniasis patients and family members.

\begin{tabular}{lccc}
\hline Cytokine & Number & pvalue & Mean +SD \\
\hline IFN- $\gamma$ in patients pg/mL & 32 & 0.006 & $37.6 \pm 64.6$ \\
IFN- $\gamma$ in family & 29 & & $5.9 \pm 14.8$ \\
IL-10 in patients ng/mL & 32 & 0.052 & $77.5 \pm 88.3$ \\
IL-10 in family & 29 & & $55.9 \pm 100.4$ \\
IL-12 in patients ng/mL & 32 & 0.001 & $798.3 \pm 639.8$ \\
IL-12 in family & 29 & & $271 \pm 178.5$ \\
\hline
\end{tabular}

Table 2. Cytokine plasma levels in visceral leishmaniasis patients, family and controls.

\begin{tabular}{lccc}
\hline Cytokine & Number & Mean \pm SD & p value \\
\hline IFN- $\gamma$ in patient group & 32 & $37.6 \pm 64.6$ & \\
IFN- $\gamma$ in family group & 29 & $5.9 \pm 14.8$ & 0.001 \\
IFN- $\gamma$ in control group & 27 & $0.18 \pm 0.49$ & \\
& & & \\
IL-10 in patient group & 32 & $77.5 \pm 88.3$ & 0.002 \\
IL-10 in family group & 29 & $55.9 \pm 100.4$ & \\
IL-10 in control group & 27 & $17.7 \pm 25.4$ & \\
& & & \\
IL-12 in patient & 32 & $798.3 \pm 639.8$ & 0.001 \\
IL-12 in family group & 29 & $271.9 \pm 178.5$ & \\
IL-12 in control group & 27 & $216.9 \pm 169.4$ & \\
\hline
\end{tabular}

The levels of cytokines in the patient group and in their family are shown in Table 1 . The serum levels of IFN- $\gamma$ and IL12 in patients were significantly higher than those of their siblings (Mann Whitney test, $\mathrm{p}<0.05$, Table 1 ). The IL-10 levels were also higher in patients than in the sibling group, but the difference was not quite significant $(\mathrm{p}=0.052)$.

When we compared the cytokine levels of all three groups with the Kruskal Wallis test (Table 2), the levels of the cytokines differed significantly. Patients had the highest levels, followed by siblings; the control group had the lowest levels.

\section{Discussion}

In VL, development of disease and control of infection depend on the effectiveness of an IFN- $\gamma$-induced innate and adaptive cellular immune response, which affects the killing of infected cells by active macrophages [11]. Exposure of humans to Leishmania donovani or Leishmania infantum can lead to either subclinical infection or overt visceral leishmaniasis, which may become life threatening. Subclinical infections are believed to be asymptomatic [12].

In our study, the levels of the serum cytokines, IL-10, IL12 , and IFN- $\gamma$, were higher in patients than in family members and control individuals.

The family group included individuals who had contact with the parasite but had no clinical manifestations. Therefore individuals with clinical manifestations had higher levels of cytokines.

In a study in south-western Ethiopia, serum cytokines (IFN- $\gamma$, IL-12, and IL-15) in 70 symptomatic VL patients were significantly higher than in 39 patients with asymptomatic leishmania infection and 12 healthy controls in the same endemic area [13].

Our data confirm previous reports that during active human VL there is an abundant production of several cytokines [13-17].

In a study in Brazil, serum cytokine levels were determined in subclinical or asymptomatic cases and lower levels of IL-10 and TNF- $\alpha$ were observed when compared to symptomatic patients [18]. In another study, plasma IFN- $\gamma$ levels were elevated during active disease, reaching $470.2 \pm 143.4 \mathrm{pg} / \mathrm{mL}$, whereas normal individuals from the same endemic area exhibited levels of $15.4 \pm 3$.8. Plasma levels of IL-10 were elevated during active disease, whereas they were undetectable in normal individuals from the same endemic area [19].

IFN- $\gamma$ has been reported to stimulate macrophage leishmanicidal activity [17,20,21]; however, high serum levels are found during active cases of VL with large parasite burdens. IFN- $\gamma$ in sera from active VL patients did not show anti-leishmanal activity, though it has been reported in sera of patients with tegumentary leishmaniasis and from recovered VL patients [17].

Lack of IFN- $\gamma$ activity may be related to the simultaneous presence of elevated levels of IL-10, as IL-10 seems to be the main macrophage-deactivating cytokine in human leishmaniasis [22,23]. Previous investigations have shown that in the plasma of VL patients, IFN- $\gamma$ and other cytokines, such as IL-10, IL-15, and TNF- $\alpha$, are increased [24/; conversely, decreased plasma concentrations of IFN- $\gamma$ in Indian [16] and 
Brazilian [25] VL patients have been reported. The low levels of IL-10 that we found in asymptomatic patients in an endemic area when compared to patients indicates control of parasite growth, lending support to an important role of this cytokine in human VL. Also, the low levels of IL-10, IFN- $\gamma$ and IL-12 in healthy siblings of patients with VL corresponds to an intermediate position between disease and protective immunity. We found a marked reduction in plasma levels of IFN-ã in the control group; therefore, normalization of the plasma levels of IFN $-\gamma$ could serve as a reliable parameter in considering the patients cured.

\section{References}

1. World Health organization. Control of leishmaniasis. Report of a WHO Expert committee. Technical Report Series, Geneva, Switzerland, 1991.

2. Caldas A., Favali C., Aquino D., et al. Balance of IL10 and interferon - gamma plasma levels in human visceral leishmaniasis: Implications in the pathogenesis. BioMed central infectious disease 2005;5:113.

3. Edrisian G.H., Nadim A., Alborzi A., Ardehali S. Visceral leishmaniasis; the Iranian experience. Archive Iranian Medical Journal 1998; $1: 22-6$.

4. Nadim A., Navid-Hamidid A., Javadian E., et al. Present status of kalaazar in Iean. Am J Trop Med Hyg 1978;27(1 p+1):25-8.

5. Pearson R.D., Sousa A.Q. A clinical spectrum of leishmaniasis. Clinical Infectious Disease 1996;22:1-3.

6. Choudhary A., A. Puri, P.Y. Guru, K.C. Saxena. An indirect fluorescent Antibody (IFA) test for the serodiagnosis of kalaazar. Journal of Communicable Disease 1992;24:32-6.

7. Barral A., Costa J.M., Bittencourt A.L., et al. Polar and subpolar diffuse cutaneous leishmaniasis in Brazil: clinical and immunopathologic aspects. Int Dermatol 1995;34(7):474-9.

8. Holaday B. Role of CD8+ T cell in endogenous interleukin -10 secretion associated with visceral leishmaniasis. Memorias do Instituto oswaldo cruz 2000;95:217-20.

9. Liew F., Millott S., Parkinson C., et al. Macrophage killing of leishmania parasites in vivo is mediated by nitric oxide from Larginine. Journal of Immunology 1990;144:4794-7.

10. Ghalib H., wittle J., Kubin M. IL-12 enhances Th1-type responses in human leishmania donovani infections. Journal of immunology 1995; $154: 4623-9$.

11. Ribeiro Jesus A., Almeida R.P., Lessa H., et al. Cytokine profile and pathology in human leishmaniasis. Braz J Med Biol Res 1998; $31: 143-8$
12. Badaro R., Jones T.C., Carvalho E.M., et al. New perspectives on a subclinical form of visceral leishmaniasis. $J$ infect Dis 1986; $154: 1003-11$.

13. Hailu A., Vander Poll T., Berhe N., Kager P.A. Elevated plasma level of interferon (IFN) - gamma, IFN-gamma inducing cytokines, and IFN-gamma inducible CXC chemokines in visceral leishmaniasis. American journal of Tropical Medicine Hygiene 2004;71:561-5.

14. Cenini P., Berhe N., Hailu A., et al. Mononuclear cell subpopulations and cytokine levels in human visceral leishmaniasis before and after chemotherapy. J Infect Dis 1993; 168:986-93.

15. Van der Poll T., Zijlstra E.E., Merissen M. Interleukin 6 during active visceral leishmaniasis and after treatment. Clin Immunol Immunopathol 1995,77:111-4.

16. Sundar S., Reed S.G., Sharma S., et al. circulating T helper 1 (Th1) cell and Th2 cell - associated cytokines in Indian patients with visceral leishmaniasis. Am J Trop Med Hyg 1997;56:522-5.

17. Barral-Netto M., Badaro R., Barral A., et al. Tumor Necrosis factor (cachectin) in human visceral leishmaniasis. J Infect Dis 1991; $163: 853-7$.

18. M.E.A Gama, J.M.L. Costa, J.C.R. Pereira, et al. Serum cytokine profile in subclinical form of visceral leishmaniasis Braz J Med Biol Res 2004;37(1)129-36.

19. Caldas A., Favali C., Aquino D., et al. Balance of IL-10 and interferon -ã plasma levels in human visceral leishmaniasis: implications in the pathogenesis BCM infect Dis 2005;5:113-21.

20. Heizel F.P., Sadick M.D., Mutha S.S., Locksley R.M. Production of interferon gamma, interleukin 2, interleukin 4, and interleukin 10 by CD4+ lymphocytes in vivo during healing and progressive murine leishmaniasis. proc Natl Acad Sci USA 1991;88:7011-5.

21. Scot P. IFN- gamma modulates the early development of T1 and Th2 responses in a murine model of cutaneous leishmaniasis. J immunol 1991;147:3149-55.

22. De Medeiros I.M., Castelo A., Salomao R. presence of circulating levels of interferon - gamma, interleukin - 10 and tumor necrosis factor - alpha in patients with visceral leishmaniasis. Rev inst Med Trop Sao Paulo 1998; 40 :31-4.

23. Carvalho E.M., Bacellar O., Brownell C., et al. Restoration of IFN- gamma production and lymphocyte proliferation in visceral leishmaniasis. J Immunol 1994;152:5949-56.

24. Cillari E., Vitale G., Arcoleo F., et al. In vivo and in vitro cytokine profiles and mono- nuclear cell subsets in sicillian patients with active visceral leishmaniasis. Cytokine 1995;7:740-5.

25. Zwingenberger K., Harms G., Pedrosa G., et al. Determinats of the immune response in visceral leishmaniasis: evidence for predominance of endogenous interleukin -4 over interferon -ã production. Clin immunol immunopathol 1990;57:242-9. 